\title{
Higher Education Research in African Contexts: Reflections from Fieldwork in Flagship Universities in South Africa, Mozambique and Ethiopia
}

\author{
Addisalem Tebikew Yallew \\ Institute for Post School Studies, Faculty of Education, University of the Western Cape, Cape \\ Town, South Africa, email: 3743398@myuwc.ac.zall addisalem.yallew@gmail.com, ORCID: \\ https://orcid.org/0000-0001-5275-6430
}

\begin{abstract}
Paul Othusitse Dipitso
Institute for Post School Studies, Faculty of Education, University of the Western Cape, Cape

Town, South Africa, email: 3742432@myuwc.ac.za, ORCID: https://orcid.org/0000-0002-

$\underline{8351-6971}$
\end{abstract}

Corresponding author:

Addisalem Tebikew Yallew

email:3743398@myuwc.ac.za/ addisalem.yallew@gmail.com

This is an Accepted Manuscript of an article to be published by Taylor \& Francis in Higher Education Research and Development (HERD) Journal.

Link to published article: https://doi.org/10.1080/07294360.2021.1877626 


\title{
Higher Education Research in African Contexts: Reflections from Fieldwork in Flagship Universities in South Africa, Mozambique and Ethiopia
}

\begin{abstract}
This article is written with the recognition that, as higher education studies evolve as a multidisciplinary area of inquiry, there is a need to reflect on the theoretical and practical concerns emerging from conducting higher education research. This is especially the case for early-career researchers who enter this relatively new field of study. This article attempts to explore the fieldwork component of the research process considering our experiences as early-career researchers conducting $\mathrm{PhD}$ studies in four universities in southern and eastern Africa. The article focuses on issues related to ethics, gaining and negotiating access to the field, and dealing with positionality during fieldwork. While reflecting on these experiences, we also attempted to explore if there are any fieldwork dynamics, which are peculiar to the African higher education context that may be considered during data collection. Reflecting on our experiences, we have argued that, in some institutions, necessary procedures for researching higher education need to be in place, while with the ones that have institutionalised mechanisms the procedures adopted need to be aligned with contextual realities and should focus on ethical considerations rather than protecting the reputation of universities. Our fieldwork experience has also made us realise that the advice given to early-career researchers both in the literature, seminars and courses they attend may not adequately prepare them for the unpredictable fieldwork dynamics. In that regard, we have suggested that there is a need to prepare emerging researchers to be open-minded, flexible, reflexive, innovative and adaptable when going out to the field.
\end{abstract}

Keywords: higher education; research; fieldwork; ethics; access; positionality; Africa 


\section{Introduction}

In this collaborative and reflective paper, we aspire to contribute to the fieldwork-related concerns encountered by researchers in higher education studies, especially for emerging scholars. As Billo and Hiemstra (2013) and Ballamingie and Johnson (2011) point out, novice researchers experience complex challenges while carrying out independent research. We also discuss the process of conducting fieldwork in universities in eastern and southern Africa, also considering contexts where higher education studies is in its earlier stages of articulation. We hold the view that doing so would offer valuable insights to scholars who intend to research the contexts studied and beyond.

As higher education studies evolve to become a relatively autonomous object-based interdisciplinary field of inquiry (Altbach, 2014; Teichler, 1996), there has been increasing scholarly engagement in terms of articulating the themes, methods and theoretical perspectives in the field (see Altbach, 1995, 2014; Case \& Huisman, 2016; Marginson, 2010; Rumbley et al., 2014; Tight, 2004, 2012, 2014). Despite these endeavours, crucial aspects involved in the actual research process that could determine the quality of the data collected, such as this reflection on fieldwork experiences, have not been explored thoroughly and remain scant. Such articles as this one could also be considered relevant in terms of strengthening the scientific rigour of higher education research and the field of inquiry.

We are writing this collaborative reflection cognizant that, although not common in higher education studies, researchers within other fields of the social sciences and humanities such as feminist and gender studies, anthropology, social work, and religious studies recognise the importance of reflecting on researchers' fieldwork experiences (Hoel, 2013; Jonbekova, 2018; Ballamingie \& Johnson, 2011; Sultana, 2007). The core issues that emerged in previous literature, which our reflection partly addresses, include researcher-participant relationships such as managing power dynamics between the researcher and participants and navigating cultural differences. Gaining access is another aspect of the research process that some studies emphasised as fundamental while reflecting on collecting data (Johl \& Renganathan, 2010; Kondowe \& Booyens, 2014; Shenton \& Hayter, 2004; Singh \& Wassenaar, 2016). Our discussion on how we navigated fieldwork experiences in universities in Ethiopia, Mozambique and South Africa, therefore, serves as a contribution to the dearth of scholarly engagement on the topic in higher education studies.

In the subsequent sections, we first present a short review of the primary fieldwork dynamics we are reflecting on in this article. This section is followed by an overview of our PhD projects and the contexts of our fieldwork. Our ensuing discussion focuses on the three aspects of fieldwork the paper reflects on, namely: ethics, negotiating access into the field, and researchers' positionality. The concluding part summarises the lessons learned from our respective experiences.

\section{Ethics, gaining access and reflecting on positionality in research}

\section{Ethics}

Research ethics and integrity require scholars to reflect on how they would address concerns such as: ensuring confidentiality, avoiding deception, gaining informed consent, negotiating power relationships, handling sensitive data, dealing with difficult participants and minimising harm. To ensure adherence, ethical guidelines and procedures are put in place by the university ethics committees, institutional review boards and professional associations (Ryen, 2014). For instance, 
in South Africa, where we are currently based, universities require researchers to obtain ethical clearances from institutional ethics committees before conducting a study.

Even though institutionalising ethical standards is fundamental for promoting research integrity, the literature reflects the need to interrogate and contextualise current and universalised institutional practices, mainly taking into account disciplinary differences and historical and sociocultural realities. It is worth noting that, especially in the social sciences, some of the requirements made by Institutional Review Boards (IRBs) have been a debatable issue (Schrag, 2010; Merrill \& Whitsel, 2017; Parsella, Amblerb \& Jacenyik-Trawogerc, 2014; Sikes \& Piper, 2010; Ntseane, 2009; Msoroka \& Amundsen, 2018). Some of the criticism regarding IRBs' requirements relates to the need to revisit ethical requirements that copy procedures from biomedical research and the failure of these procedures to capture researcher-participant relationships on the ground (Burgess, 1984; Hunter, 2018; Israel \& Hay, 2006; Sikes \& Piper, 2010; Scheyvens, 2014; Van den Hoonaard, 2014). Studies also suggest tensions between IRBs' practices that are often informed by 'Western' research standards and contextual realities within African and beyond (Ntseane, 2009; Msoroka \& Amundsen, 2018; Sultana, 2007). Expounding on such tensions, Sikes and Piper (2010, p. 211) further state that an increasing number of students across the globe are now reflecting "on the need to be aware of the ways in which the imposition of Western ethics requirements do not always meet local conditions and can be experienced as yet another example of colonisation." IRBs are also accused of playing gatekeepers concerned with mainly avoiding controversy rather than addressing ethical concerns (Cannella \& Lincoln, 2007; Tierney \& Corwin, 2007; Sikes \& Piper, 2010). According to Sikes and Piper (2010, p. 207), IRB practices might have negative implications for academic freedom in that they have a tendency "to limit, control and even stop particular research from being done and particular areas of the enquiry being explored." Our article, therefore, focuses on critically evaluating our fieldwork experiences, keeping in mind the necessity of conducting ethical research while at the same time investigating if there are any practical and contextual concerns that need reflection.

\section{Access}

Like other fieldwork dimensions, Burgess (1984) holds the view that access is not a linear process because it involves back and forth communication with relevant gatekeepers and participants operating under different institutional contexts. The literature on negotiating and gaining access also reveals that gatekeepers play a crucial role in enabling researchers to access and establish research relationships with participants, which allow them to acquire credible data (Clark, 2011; Kondowe \& Booyens, 2014; Hett \& Hett, 2013; Reeves, 2010). Issues concerning the inability to gain access to research fields include challenges related to physical and social access as well as poor communication and relationships with research participants and gatekeepers (Singh \& Wassenaar, 2016). The complex process of negotiating access, therefore, requires a researcher to understand the hierarchical procedures in institutions regarding data collection among other concerns. As Burgess (1984) argues, understanding this enables the researcher to identify patterns of social relationships within the research site. Additionally, maintaining productive relationships requires the researcher to establish ethical relations with participants that are supported by effective communication and mutual trust (Hett \& Hett, 2011). We set out, therefore, to chronicle our fieldwork experiences, keeping in mind that employing effective strategies to engage with gatekeepers and participants were crucial for the overall success of our respective projects. 


\section{Positionality}

England (1994) argues that fieldwork is a dialectical process structured by the researcher and participants, whereby the researcher's positionality directly affects this process. In effect, while reflecting on fieldwork experiences, it becomes crucial to acknowledge the significance of one's positionality and its implications on a research project. This relates to the idea that positionality affects the identity of a researcher which, in turn, influences their approach to conducting fieldwork (Giampapa, 2011). Recognising positionality also entails a self-introspective and critical reflexive exercise, which ultimately identifies power relations embedded within the research process as well as researchers' relationships with the various categories of participants they encounter during fieldwork by considering variables such as language, culture, race, ethnicity, gender and sexuality (Bourke, 2014; Crossa, 2012). In this paper, we also hold the view that reflexive analysis on one's position in a given field plays a vital role with regards to obtaining reliable data (Chereni, 2014).

Furthermore, reflections on positionality enable researchers to gain insights on how to approach the research setting and participants by revealing individual biases and subjectivities that might affect the research process (Bourke, 2014). It is worth noting that in any research project it is often difficult to maintain neutrality, for the perceptions that an individual researcher holds with regard to the topic may not be eliminated. Besides the above aspects, another dimension that researchers reflect on regarding their positionalities relates to their status as to whether they are insiders or outsiders to the field that they navigate.

All in all, it is worth mentioning that the literature on positionality reveals that little attention has been given to the level of researchers' experience and its implications for the research process. Reflections on the positionality of researchers also often focus on power differentials that exist between the perceived power and privilege of the researchers vis-a-vis their research 'subjects'. The reflections hardly focus on the power dynamics that arise when researching the researchers themselves. As PhD students, one of the questions we kept in mind while conducting this reflection was: how do we navigate researching the traditionally powerful and privileged in academia since "Academic researchers represent centres of power, privilege, and status within their formal institutions, and within the production of scientific knowledge itself" (Muhammad et al., 2014, p. 1046).

\section{Method}

To undertake this collaborative reflection, we adopted an autoethnographic approach. We deemed this method appropriate since our objective was to capture our experiences as emerging researchers by combining autobiography and ethnography being grounded on the paradigmatic tenets of constructive-interpretivism (McIlveen, 2008) viewing knowledge about a phenomenon as an interpreted experience. Autoethnography was employed in the broadest sense as this article seeks to describe and analyse our personal experiences to understand cultural and social experiences by conducting a transparent and critical analysis, taking into account the social contexts where fieldwork is conducted (Ellis, Adams \& Bochner, 2011; Hamilton, 2008). This is also an attempt to utilise our reflexive narratives to creatively highlight the often undisclosed and underemphasised experiences of the research process such as fieldwork (Schmid, 2019). In line with autoethnographic traditions, we consulted our copious field notes, our respective research journals and audio recordings to describe and analyse how we navigated and negotiated issues related to 
ethics, access and positionality for our respective $\mathrm{PhD}$ projects in universities in Ethiopia, Mozambique and South Africa.

Our collective account is also an attempt at engaging with student voices and experiences in conducting higher education research. Even though our work is not autobiographical per se, as Tight (2003) states in a notable work on researching higher education, autobiographical accounts are used to a lesser extent for exploring student experiences, although they are quite common in research pertaining to academic work.

\section{Setting the context for the two studies and sites of fieldwork}

This collaborative reflection is based on our fieldwork experiences in four public universities that claim to be research-oriented. Even though leading research universities in their respective contexts, the universities in Ethiopia and Mozambique are still more teaching and learning oriented than research, and turning the research lens on the institutions themselves is still in the early stages. The universities in South Africa are, however, in a much more advanced position than universities in both Ethiopia and Mozambique in terms of institutionalising higher education research since they have established procedures to obtain ethical clearances, contacting gatekeepers and obtaining access to research participants. Above all, when compared to established research cultures in North America or Europe, the culture of reflexively and systematically looking into higher education is not well-developed in the African contexts studied.

Concerning our reflections on fieldwork dynamics, it is worth noting that though the universities where we collected data share common characteristics with other universities globally in terms of having shared visions and missions, we were cognizant that they (and by implication our research participants) are also shaped by their respective contextual and national cultures. For instance, following Hofstede's (2020) national culture dimensions, the four universities are all located in hierarchical national cultures with high power distances. They are also predominantly located in collectivist (Ethiopia and Mozambique) and masculine (Ethiopia and South Africa) cultural contexts.

The fieldwork activities for our PhD projects were mainly conducted between June 2018 and April 2019. Table 1 summarises our respective projects, their focus and methodologies.

Table 1

Background information for the two projects

\begin{tabular}{lll}
\hline $\begin{array}{l}\text { Research } \\
\text { dimension }\end{array}$ & \multicolumn{1}{c}{ Research project 1 } & \multicolumn{1}{c}{ Research project 2 } \\
\hline \multicolumn{1}{c}{ Focus } & $\begin{array}{l}\text { Exploring the implications of } \\
\text { using English for research and } \\
\text { publication }\end{array}$ & $\begin{array}{l}\text { Investigating the implications of } \\
\text { work-integrated learning on } \\
\text { graduate employability }\end{array}$ \\
$\begin{array}{l}\text { Research paradigm } \\
\text { Research design }\end{array}$ & $\begin{array}{l}\text { Qualitative study } \\
\text { Multiple case study } \\
\text { Instruments of data }\end{array}$ & $\begin{array}{l}\text { Interviews } \\
\text { Mixed methods research }\end{array}$ \\
\hline
\end{tabular}


The first research (Yallew, 2019) investigated the aspects related to the implications of the increasing use of the English language for research and publication in multilingual African contexts. The fieldwork for this research was conducted in Ethiopia and Mozambique. The research employed a qualitative multiple case-study design. In-depth interviews served as the primary instruments to collect data from researchers across disciplines and university leaders involved in managing research and developing research policies. The data for the study was mainly collected from three fieldwork trips to each of the universities in Ethiopia and Mozambique.

The second research explored work-integrated learning and its implications for employability for mining engineering undergraduates in two universities in South Africa. The study adopted a mixed-methods approach. A qualitative exploratory study was initially undertaken to obtain perspectives of mining engineering lecturers, workplace supervisors and mining engineers concerning work-integrated learning. Secondly, the study utilised a quantitative approach to measure work readiness for mining engineering undergraduates.

\section{Discussion}

This discussion is based on the dimensions of the fieldwork covered in earlier sections. It focuses, therefore, on providing narrative accounts of our experiences related to (1) procedures of obtaining ethical clearances (2) negotiating access to the field and research participants, and (3) reflections on our positionalities as we collected data.

\subsection{The process of obtaining ethical clearance and accessing research sites}

Prior to starting our fieldwork, we both applied for ethical clearance from our university after acceptance of our research proposals as per the university regulations. By following institutional ethical guidelines for research integrity, we ensured that our studies adhered to the critical principles of ethics in research, namely: informed consent, privacy, confidentiality and anonymity before embarking on collecting data. However, it is noteworthy to indicate that both our studies had little possibility of causing harm to the research participants. It is also worth mentioning that contacting gatekeepers started as soon as our proposals were approved as this paved the way for a more predictable, practical and manageable data collection experience.

The procedures for gaining access to data varied across university contexts. For the study on the English language and its implications for research and publication, permission from top-level university management was enough in Mozambique. In the Ethiopian university, however, there were no explicit provisions as to how a researcher from another institution could proceed with fieldwork. On the other hand, a South African university where this study was supposed to be conducted declined to provide clearance after requesting several documents in addition to the original ethical clearance provided by our home university. The outcome of the ethical clearance application to this South African university which took several months was communicated to the researcher in a brief letter stating, "After serious consideration and consultation, it has been decided not to grant permission to you to include this institution in your research project." In this particular South African university, efforts by the $\mathrm{PhD}$ researcher to get further clarification as to what the institutional expectations were with regards to ethics were handled by the person 
responsible for institutional marketing. These uncertainties and variations concerning clearance to conduct the study created delays for data collection and analysis.

Upon starting fieldwork in South African universities where research on investigating workintegrated learning was conducted, the researcher was informed by the university departments that to conduct an ethical study clearance needed to be granted by the respective institutions. The clearance applications took quite a while to be completed because they included back and forth communication with the departments where the study was to be conducted. In one university, the officers who were processing applications for ethics seemed to be sceptical about the study. They were concerned about the reasons the researcher intended to study their university and how the findings would ultimately be presented. They further raised concerns that in previous studies researchers presented results in a way that tarnished the university brand. This account reveals that these departments value ethical research. However, the clearance procedures presented challenges to the researcher.

Other critical issues related to the ethical requirements that emerged during our collaborative reflections related to ensuring participant confidentiality and having signed consent forms. In some instances, the university procedures required us to precisely identify whom we wanted to contact to gain data, which in turn compromised the confidentiality we intended to guarantee for our research participants. We also noticed that in universities where conducting institutional research in higher education is not common, like in Ethiopia and Mozambique, there were instances where participants found it odd or even suspicious that they were required to sign consent forms.

As several scholars argued (Burgess, 1984; Hunter, 2018; Israel \& Hay, 2006; Parsella, Amblerb \& Jacenyik-Trawogerc, 2014; Van den Hoonaard, 2014), we also ended up questioning if ethical procedures that are inspired by the biomedical sciences are appropriate to the social sciences, particularly in the African higher education contexts studied. For instance, when it comes to ensuring voluntary participation, one may question the applicability of the overly rigorous ethical approval procedures borrowed from the medical sciences into the context of higher education where the chances of coercing research participants into contributing to studies are minimal. As Ntseane (2009) argued, we also see the need to modify the ethical standards in higher education research to accommodate the diversity that arises from cultural variations which were identified within the universities studied.

Another ethics-related issue that our joint reflections brought to the fore concerns the role played by IRBs, which led us to argue that more scrutiny of their roles needs to be made, especially in higher education research where the very institutions that grant clearances become the objects of research. As suggested in the literature (Cannella \& Lincoln, 2007; Tierney \& Corwin, 2007; Sikes \& Piper, 2010), institutions could easily use the current procedures as tools to gatekeep what is researched about them and what is not, thereby creating unethical research practices in the name of policing ethics. This might be especially the case for research topics that institutions and departments might perceive as sensitive, political and troublesome.

We observed institutional practices within our home universities that might pose challenges especially to $\mathrm{PhD}$ students. The institutional mechanisms where ethical clearance application outcomes are not sent directly to the principal investigator, i.e. the student, but the supervisor could cause delays if supervisors fail to communicate the outcomes of applications to graduate students in a timely manner. As such, having no direct access to the application process could also create uncertainties for $\mathrm{PhD}$ students regarding the approval time for both research proposals and ethical clearance applications. 


\subsection{Access to gatekeepers and participants}

As researchers for our respective projects, we were not members of the universities that we researched. Therefore, we considered ourselves as outsiders to the particular contexts. This implies that we were not fully aware of the internal dynamics of those institutions and the various gatekeepers in them. As a result, with regard to securing access to gatekeepers and participants, establishing prior contacts and using people on the inside were the main strategies we both adopted in our studies. These strategies assisted both of us to navigate the systems and departments and obtain data for our respective projects. In line with what Crowhurst (2013) suggested, we went into the field cognizant that gaining access is much more concerned with how a researcher manages and maintains relationships with gatekeepers.

In the study that investigated work-integrated learning, the participants included a purposefully selected group of lecturers and undergraduate students. In one university, contact was made initially with the lecturers via email. It was easy to contact the participants in this university because the contact information on the institution's website was updated. However, difficulties were encountered when directly recruiting participants using their email addresses without a buyin from the head of the department. For the survey, a link to the questionnaire was sent initially to the university registrar, and later it was forwarded to students. Since the response rate was not satisfactory, links to the survey and subsequent remainders were sent to the students directly after obtaining mailing lists from the contact person in the concerned department. Ultimately, this assisted in increasing the response rate and quality of response. In the second university, contact was made with the departmental secretary, who then assisted in facilitating communication with the lecturers about the research project. They set appointments based on their availability, making it easier for conducting these interviews. As for the students, they were given hard copies of the printed questionnaires. However, the response rate was still very poor. As a result, a decision was made to send them links via email, which assisted to increase the responses. One more strategy adopted as an alternative that further increased the rate of response was to seek the assistance of a student participant who then sent the link to other fellow participants' mobile phones.

For the study focusing on the English language and its implications for researchers and research-oriented universities, participants were recruited purposively considering disciplinary variations and through the research offices of the universities and respective faculties. Some of the challenges the researcher faced included several forgotten and cancelled appointments because of the many meetings and lectures participants had to attend and other factors such as power outages. As a PhD student interviewing seasoned researchers and higher education leaders, the researcher also had to be extra assertive to be taken seriously. The other challenge that required patience and flexibility with this project was related to obtaining visas to Mozambique. For instance, in the first round of data collection, the researcher was allowed to stay in Mozambique for not more than one month. Since two and a half weeks were spent attempting to obtain clearance from the university authorities, leaving the researcher with insufficient time to schedule and conduct interviews, the researcher had to make a second-round trip to the country to collect the bulk of the data for the research. However, still more data was required from the Mozambican context, but given the more stringent visa requirements and the considerable amount of time and resources the trip would take, the researcher resorted to conducting Skype and WhatsApp interviews to finalise the data collection process.

As per our collective experience of dealing with participants both within universities and outside, we would like to forward the following tips for emerging and other researchers who wish 
to conduct their studies in contexts like the ones we studied. First is the need to familiarise oneself not only with the institutional culture but national cultures as well. The second one is to establish contacts while waiting for ethical and other clearances to come through to make the best use of the limited time during data collection. The third is the importance of building rapport and trust with participants. Collecting data in universities also demands plenty of patience, flexibility and constant follow-ups on the side of the researcher since appointments can be delayed and even cancelled. In some instances, getting one interview required rescheduling an interview seven times. Talking to busy and overworked university leaders also involves waiting in corridors for several hours for many days, and could involve dealing with multiple gatekeepers and knocking on many doors beforehand.

Above all, a researcher should be prepared for unpredictability. We noticed that the best time to research participants is in the morning before they embark on their day-to-day activities in the university. It is also a good practice to request participant phone numbers once the rapport is established and once they are aware of the research agenda. This helps the researcher to have some sense of control in that one can check in advance if scheduled interview meetings are going to happen. Email might not work since in all institutions where we conducted the studies many of the participants may not respond to emails as fast as they would with phones. In this manner, taking phone numbers could also help researchers avoid encounters with gatekeepers who at times may make the data collection process needlessly difficult.

There are also a few lessons we learned while managing relationships with participants that require patience and understanding when conducting research in contexts such as the African universities which we studied. One of the lessons is that qualitative studies seem to be less understood, especially among researchers in the natural sciences and engineering who come from the predominantly quantitative research traditions. Perhaps because higher education studies as a field of inquiry is new to participants, another lesson we learned is the need to clearly explain the objectives of projects. Doing so and obtaining the required data required striking a delicate balance between being assertive but not too overly assertive so that hierarchies that are the characteristics of contexts with high power distance are respected (Hofstede, 2020).

\subsection{Positionality}

One of the crucial concerns to revisit in cross-cultural educational research with regards to analysing one's positionality and its complex implications for fieldwork is the 'insiderness' and 'outsiderness' of the researcher (Aaltio \& Hopfl, 2009; Berger, 2015; Milligan, 2016). We can be positioned in the hazy category of being neither outsiders nor insiders in relation to the field of higher education since we both have some experience working as academic members in higher education institutions. However, we were outsiders to the universities studied, and this provided both opportunities and challenges. On the one hand, we agreed that being perceived as outsiders aided us to obtain more reliable and trustworthy data in that our participants were relatively more open to discussing their views that they would have otherwise not shared if an insider researcher approached them. Nonetheless, as relative outsiders, we spent a considerable amount of time making adjustments in terms of understanding not only institutional cultures but also the national cultures, norms and values to obtain more reliable data.

We were conscious of various demographic variables concerning our research participants, which included; age, gender, race, language and educational background. In the context of South Africa, the researcher, a black man from Botswana, was aware of the race of the participants 
because the majority of them were white. In this regard, the possible perceptions of cultural differences were minimised through self-reflexivity. Moreover, we were well aware that we did not share similar linguistic and academic backgrounds with some of the participants. Since the South African, Ethiopian and Mozambican contexts are characterised by high linguistic diversity, we anticipated some linguistic barriers between us and participants whereby participants might not fully understand what we were requesting from them. Therefore, to avoid such barriers, we both used simple and nontechnical language in communicating the objectives of our studies and in designing data collection instruments. We also made provision for translating interview instruments and the questionnaires, since we did not speak some of the major languages spoken as first languages by our participants (Portuguese in Mozambique, and Afrikaans, isiZulu, isiXhosa in South Africa). However, we later learned that, except for some participants from Ethiopia, almost all our respondents were comfortable with being interviewed and completing questionnaires in English. We surmise that the Ethiopian participants who preferred to be interviewed in the local language, Amharic, opted to do so because the researcher conducting this study is an Ethiopian herself.

Our experiences are also in alignment with Scheyven's (2014) argument that when researchers recognise the power dynamics of relationships, it is possible to make conscious strategic choices to minimise discomfort in participants, thereby making the research process more rewarding for participants and researchers. Depending on who we were engaging with in the institutional and cultural hierarchies, our experiences also suggest that being positioned as PhD students in the highly hierarchical higher education systems and cultural contexts granted us some social prestige on the one hand and was a disadvantage on the other. Undergraduate and postgraduate students viewed us with high regard whereas, at times, the opposite occurred with senior researchers as some of them were either reluctant to talk to us or did not take our projects seriously enough to participate.

\section{Conclusion}

This paper discussed the fieldwork experiences of emerging researchers in higher education from an African perspective. The central focus was on navigating issues related to obtaining ethical clearances, negotiating access to research sites, and reflecting on researchers' positionality. Though the fieldwork challenges we encountered could be seen as unique to our respective research projects, the critical lessons highlighted from these experiences could be insightful to all novice researchers in the emerging field of inquiry.

In terms of ethics, we had to navigate complex institutional procedures and practices to start data collection. In some institutions, there were no clearly stated rules on ethical and research clearance. In contrast, other institutions seem to instil strict procedures that, at the same time, seem to leave decisions at the discretion of gatekeepers and people in charge of institutional marketing. We also observed that some of the bio-medical research inspired ethical guidelines and standards might not only be context-sensitive but also might end up jeopardising the chances of obtaining authentic and trustworthy data. In this regard, we see the need to tailor ethics application and clearance procedures, considering the field of higher education studies. This reflective paper also contends that more research needs to be done to critically investigate the structure and the role of the institutional ethics committees in higher education on the continent. Questions in this regard could include: what informs the procedures of ethical clearance, from where do the boards draw ideas and practices, and who holds them accountable? 
Concerning access to research sites, gatekeepers and participants, we have learned the importance of flexibility, patience and persistence. This is especially the case for universities in Ethiopia and Mozambique, where higher education research is a relatively new field of inquiry. In these universities, negotiating access and recruiting interview participants for interview-based qualitative studies were also challenging. This might be attributable to predominantly positivist research traditions where key gatekeeping positions are occupied by researchers from traditionally 'hard' sciences. Academic staff from those disciplines who participated in the research also found the process of conducting interview-based studies unfamiliar, and this required the researcher to exert extra effort to clarify aspects related to the research.

Our experiences as novice researchers in higher education studies collecting data in four research-oriented universities in Ethiopia, Mozambique, and South Africa also suggest that, even though these universities emphasise research intensity, commitment seems to be lacking when they become objects of inquiry. Claims of research-orientedness do not seem to be matched with research ecosystems that are conducive for higher education research. As indicated elsewhere, they appear to have confusing, at times non-existent, and at times very strict but the market and imageoriented procedures that pose challenges to higher education researchers.

We suggest, therefore, the following macro, meso, micro-level interventions and recommendations for higher education systems, institutions, postgraduate schools, early-career researchers and higher education researchers in general. Firstly, especially in contexts where higher education research is in its earlier stages of evolution, there is a need to turn the research lens on the processes involved in conducting such research. There is also a need to institutionalise higher education research in such contexts, but considerations need to be made for field and context specific factors. Early-career researchers, $\mathrm{PhD}$ supervisors, and postgraduate schools in higher education studies also need to give due attention to the need to undertake a nuanced culturesensitive and reflexive pre-fieldwork analysis of national, institutional and disciplinary cultures in addition to mastering the technical aspects of obtaining clearance, gaining access and negotiating considering one's positionality. Handbooks and guidelines could be prepared to enhance the knowledge and skills of emerging researchers in this regard. We also would like to argue that there is a need for more reflexivity and reflexive articles like this as one way of enriching the emerging field of higher education studies.

Conducting the kind of research we have undertaken is also a resource and time-intensive endeavour requiring multiple trips, visas, and uncertainties to access. The case study approach we both adopted for our studies also required time to familiarise ourselves with the contexts studied and obtain reliable data. In addition, conducting cross-national studies in contexts other than the ones we are familiar with further complicated fieldwork challenges. Doctoral programmes and funding modalities could be designed to take into account these uncertainties and unpredictability surrounding collecting data, especially in contexts where higher education studies is emerging as a field of inquiry.

\section{Acknowledgements}

We would like to thank the Carnegie Corporation of New York for funding both our studies through scholarships.

\section{Disclosure statement}

The authors of this article report no potential conflict of interest. 


\section{References}

Aaltio, I., \& Hopfl, H. J. (2009). Reflexivity in research: The role of the researcher, the research process, and the nature of facts in the study of organisations. Journal of Critical Postmodern Organisation Science, 7(7.3), 6-8.

Altbach, P. G. (2014). The emergence of a field: Research and training in higher education. Studies in Higher Education, 39(8), 1306-1320.

Altbach, P. G. (1995). Research on higher education: Global perspectives. Educational Practice and Theory, 17(2), 3-18.

Ballamingie, P., \& Johnson, S. (2011). The vulnerable researcher: Some unanticipated challenges of doctoral fieldwork. The Qualitative Report, 16(3), 711-729.

Berger, R. (2015). Now I see it, now I don't: Researcher's position and reflexivity in qualitative research. Qualitative Research, 15(2), 219-234.

Billo, E., \& Hiemstra, N. (2013). Mediating messiness: Expanding ideas of flexibility, reflexivity, and embodiment in fieldwork. Gender, Place \& Culture, 20(3), 313-328.

Bourke, B. (2014). Positionality: Reflecting on the research process. The Qualitative Report, 19(33), 1-9.

Burgess, R. G. (1984). The research process in educational settings: Ten case studies. Lewes: Falmer Press.

Case, J. M., \& Huisman, J. (Eds.). (2016). Researching higher education: International perspectives on theory, policy and practice. London: Routledge.

Cannella, G. S., \& Lincoln, Y. S. (2007). Predatory vs. dialogic ethics constructing an illusion or ethical practice as the core of research methods. Qualitative Inquiry, 13(3), 315-335.

Carpenter, D. (2018). Ethics, reflexivity and virtue. In Iphofen, R., \& Tolich, M. (Eds). The Sage handbook of qualitative research ethics (pp 35-50). California: Sage Publications.

Chereni, A. (2014). Positionality and collaboration during fieldwork: Insights from research with co-nationals living abroad. In forum qualitative sozialforschung/forum. Qualitative Social Research, 15(3), 1-21.

Clark, T. (2011). Gaining and maintaining access: Exploring the mechanisms that support and challenge the relationship between gatekeepers and researchers. Qualitative Social Work, 10(4), 485-502.

Crossa, V. (2012). Relational positionality: Conceptualising research, power, and the everyday politics of neoliberalization in Mexico City. ACME: An international E-journal for critical geographies, 11(1), 110-132.

Crowhurst, I., \& Kennedy-Macfoy, M. (2013). Troubling gatekeepers: Methodological considerations for social research. International Journal of Social Research

Methodology, 16(6), 457-462.

Ellis, C., Adams, T. E., \& Bochner, A. P. (2011). Autoethnography: An overview. Historical Social Research/Historische sozialforschung, 12(1), 273-290.

England, K., V. (1994). Getting personal: Reflexivity, positionality, and feminist research. The Professional Geographer, 46(1), 80-89.

Hett, G., \& Hett, J. (2013). Ethics in intercultural research: Reflections on the challenges of conducting field research in a Syrian context. Compare: A Journal of Comparative and International Education, 43(4), 496-515.

Giampapa, F. (2011).The politics of "being and becoming" a researcher: Identity, power, and negotiating the field, Journal of Language, Identity \& Education, 10(3), 132-144. 
Israel, M., \& Hay, I. (2006). Research ethics for social scientists. London: Sage.

Hamilton, M. L., Smith, L., \& Worthington, K. (2008). Fitting the methodology with the research: An exploration of narrative, self-study and auto-ethnography. Studying Teacher Education, 4(1), 17-28.

Hoel, N. (2013). Embodying the field: A researcher's reflections on power dynamics, positionality and the nature of research relationships. Fieldwork in Religion, 8(1), 27-49.

Hofstede, G., (2020). Compare Countries - Hofstede insights. [online] Hofstede Insights. Available at: <https://www.hofstede-insights.com/product/compare-countries/> [Accessed 14 August 2020].

Hofstede, G. (2001). Culture's consequences: Comparing values, behaviors, institutions and organisations across nations. London: Sage.

Johl, S. K., \& Renganathan, S. (2010). Strategies for gaining access in doing fieldwork: Reflection of two researchers. The Electronic Journal of Business Research Methods, 8(1), 42-50.

Jonbekova, D. (2018). Educational research in Central Asia: Methodological and ethical dilemmas in Kazakhstan, Kyrgyzstan and Tajikistan. Compare: A Journal of Comparative and International Education, 50(3), 1-19.

Kondowe, C., \& Booyens, M. (2014). A student's experience of gaining access for qualitative research. Social Work Journals, 50(1), 146-152.

Marginson, S. (2010). Higher education as a global field. In Global creation: Space, mobility and synchrony in the age of the knowledge economy (pp. 201-228). New York: Peter Lang Publishing.

McIlveen, P. (2008). Autoethnography as a method for reflexive research and practice in vocational psychology. Australian Journal of Career Development, 17(2), 13-20.

Merrill, M. C., \& Whitsel, C. (2017). Institutional review boards and intercultural research Barriers. In Silova, I., Sobe, N.W., Korzh, A., \& Kovalchuk, S. (Eds.). Reimagining utopias. Bold visions in educational research (pp. 143-161). Rotterdam: Sense Publishers.

Milligan, L. (2016). Insider-outsider-inbetweener? Researcher positioning, participative methods and cross-cultural educational research. Compare: A Journal of Comparative and International Education, 46(2), 235-250.

Msoroka, M. S., \& Amundsen, D. (2018). One size fits not quite all: Universal research ethics with diversity. Research Ethics, 14(3), 1-17.

Muhammad, M., Wallerstein, N., Sussman, A. L., Avila, M., Belone, L., \& Duran, B. (2015). Reflections on researcher identity and power: The impact of positionality on community based participatory research (CBPR) processes and outcomes. Critical Sociology, 41(7-8), 1045-1063.

Ntseane, P. G. (2009). The ethics of the researcher-subject relationship: Experiences from the field. In Mertens, D. M., \& Ginsberg, P. E. (Eds.). The handbook of social research ethics (pp. 295-307). Thousand Oaks: Sage Publications.

Parsell, M., Ambler, T., \& Jacenyik-Trawoger, C. (2014). Ethics in higher education research. Studies in Higher Education, 39(1), 166-179.

Reeves, C. L. (2010). A difficult negotiation: Fieldwork relations with gatekeepers. Qualitative Research, 10(3), 315-331.

Ryen, A. (2011). Ethics and qualitative research. In D. Silverman (Ed.). Qualitative research (pp. 416-438). London: Sage. 
Rumbley, L. E., Altbach P. G., Stanfield, D. A., Shimmi, Y, de Gayardon, A., \& Chan, R. Y. (2014). Higher education: A worldwide inventory of research centers, academic programs, and journals and publications (3rd ed.). Bonn, Germany: Lemmens Media.

Shenton, A. K., \& Hayter, S. (2004). Strategies for gaining access to organisations and informants in qualitative studies. Education for Information, 22(3-4), 223-231.

Schmid, J. (2019). Autoethnography: Locating the self as standpoint in post-apartheid South Africa. In Laher,S., Fynn, A., \& Kramer, S. (Eds.). Transforming research methods in the social sciences: Case studies from South Africa (pp. 265-279). Johannesburg: Wits University Press.

Sikes, P., \& Piper, H. (2010). Ethical research, academic freedom and the role of ethics committees and review procedures in educational research. International Journal of Research \& Method in Education, 33(3), 205-213.

Sultana, F. (2007). Reflexivity, positionality and participatory ethics: Negotiating fieldwork dilemmas in international research. ACME. An International E-journal for Critical Geographies, 6(3), 374-385.

Teichler, U. (1996). Comparative higher education: Potentials and limits. Higher Education, 32(4), 431-465.

Tierney, W. G., \& Corwin, Z. (2007). The tensions between academic freedom and institutional review boards. Qualitative Inquiry, 13(3), 388-398.

Tight, M. (2004). Research into higher education: An a-theoretical community of practice? Higher Education Research \& Development, 23(4), 395-411.

Tight, M. (2003). Researching higher education. Berkshire, UK: Society for Research into Higher Education \& Open University Press.

Tight, M. (2014). Discipline and theory in higher education research. Research Papers in Education, 29(1), 93-110.

Van den Hoonaard, W. C. (2014). The "ethics rupture'" Summit, Fredericton, New Brunswick, Journal of Empirical Research on Human Research Ethics, 8(1), 3-7.

Yallew, A. T. (2019). The Expanding use of the English language for research and its Implications for Higher Education Institutions and Researchers. Journal of Comparative \& International Higher Education, 11(Winter), 209-212. 